\title{
İstanbul Boğazı Geçişi Güvenlik Açığı: Olası Tanker Patlama Simülasyonu
}

\author{
Müge Ensari Özay ${ }^{1 *}$, Hasan Köten², Emine $\operatorname{Can}^{3}$ \\ ${ }^{1}$ Üsküdar Üniversitesi, Sağllk Bilimleri Fakültesi, İs Sağllğı ve Güvenliği Bölümü, İstanbul, Türkiye

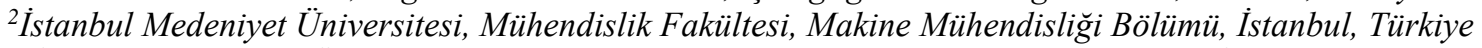 \\ ${ }^{3}$ İstanbul Medeniyet Üniversitesi, Mühendislik Fakültesi, Fizik Mühendisliği Bölümü, İstanbul, Türkiye

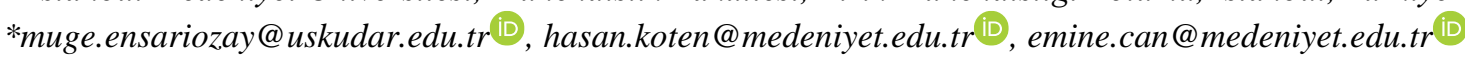 \\ Makale gönderme tarihi:07.08.2021, Makale kabul tarihi: 22.11.2021
}

\begin{abstract}
$\ddot{\mathbf{O} z}$
Deniz kazaları araştırmaları, kazalarda teknik, insani, operasyonel ve organizasyonel olmak üzere pek çok risk faktörünün önemli etkilere sahip olduğunu göstermektedir. Özellikle kritik öneme sahip olan lokasyonlarda olan kazaların sonuçları ciddi hasarlara ve yıkıma neden olabilmektedir. Mevcut risk değerlendirmelerinde teknik güvenlik sistemlerine odaklanırken, patlama modellemesi çalışmaları büyük önem taşımaktadır. Bu çalışmanın ana amacı, İstanbul Boğazından geçen ve sıvılaştırılmış doğalgaz (LNG) taşıyan tankerlerde olası bir tank patlaması ve yangın durumunda kazanın etki alanlarını incelemektir. Çalışmada açık erişim olan ALOHA yazılım programı kullanılarak 10,000 $\mathrm{m}^{3}$ 'lük LNG tankında BLEVE senaryosu analiz edilmiştir. Patlamanın yaklaşık 4.4 km'lik tehdit bölgesinde binaların tahrip olmasına, ciddi yaralanmalara ve camların kırılmasına neden olabileceği belirlenmiş̧ir. Ayrıca $2.0 \mathrm{~km}$ 'lik tehdit bölgesinde $10.0 \mathrm{~kW} / \mathrm{m}^{2}$ termal radyasyon oluşacağı ve 60 saniye içinde potansiyel olarak ölümcül olacağı saptanmıştır. Olası patlama modellemesi sonucunda İstanbul Boğazında çok büyük bir felaket yaşanacağı öngörülmektedir.
\end{abstract}

Anahtar Kelimeler: ALOHA, deniz kazası, deniz ulaşımı, İstanbul Boğazı, LNG, patlama

\section{Transition Vulnerability in the Strait of Istanbul: Possible Tanker Explosion Simulation}

\begin{abstract}
Researches on maritime accidents show that many risk factors, including technical, human, operational and organizational, have important effects on accidents. The consequences of accidents, especially in critical locations, can cause critical damages and destructions. While focusing on technical safety systems in current risk assessments, explosion modeling studies has great importance. The main purpose of this study is to examine the impact area in the event of a possible tank explosion and fire in tankers carrying $10,000 \mathrm{~m}^{3}$ liquefied natural gas (LNG) passing through the strait of Istanbul. In this study, the BLEEVE scenario in the LNG tank was analyzed using the open access ALOHA software program. It has been determined that the explosion could cause the destruction of buildings, serious injuries and shattering windows in the threat area of approximately $4.4 \mathrm{~km}$. Furthermore, it has been determined that $10.0 \mathrm{~kW} / \mathrm{m}^{2}$ of thermal radiation will occur in the $2.0 \mathrm{~km}$ threat zone and will be potentially lethal within 60 seconds. As a result of the possible explosion modeling, it is forseen that there is a great disaster in the strait of Istanbul.
\end{abstract}

Keywords: ALOHA, Accident at sea, explosion, LNG, sea transportation, the strait of Istanbul

\section{GİRIŞ̧}

Ülkemiz sınırları içerisinde bulunan boğazlar bölgesi Montreaux Boğazlar Sözleşmesi şartları kapsamında Türkiye'nin egemenliğinde uluslararası trafiğe açık su yolu olarak tanımlanmıştır. Montreaux Sözleşmesinin (1936) 2. maddesine göre barış zamanında, ticaret gemileri, gündüz ve gece, bayrak ve yük ne olursa olsun, hiçbir işlem olmaksızın, Boğazlardan geçiş ve gidiş-geliş (ulaşım) tam özgürlüğünden yararlanacaklardır, kılavuzluk ve römorkörcülük isteğe bağlıdır. Türk Boğazları Deniz Trafik Düzeni Yönetmeliği'ne (2019) göre Türk Boğazlarından geçmek isteyen gemiler için Türk Boğazlarında Rapor Sistemi (TÜBRAP) ve gemiler tarafindan doldurulması gereken raporlar, gemilerin uyması gereken kurallar, geçiş rotaları ve demirleme yerleri detaylı bir şekilde verilmiştir. İstanbul ve Çanakkale Boğazlarından geçen gemiler dünya ham petrol ticaretinin \%3 ile \%8'i oluşturmaktadır 
(Küçükosman ve Bilgin, 2019). Boğazlarda oluşabilecek kazaları engellemek için 1994 ve 1998 yıllarında düzenlenen Boğazlar Geçiş Tüzükleri (TBDTDT) ile boğaz geçişlerine can, mal ve seyir emniyetini sağlamak amacıyla bazı kısıtlamalar getirmiştir. Bu tüzüklerde boğazlarda trafik ayrım şemaları, boy ve tonaj kısıtlamaları, hız sınırlamaları ve seyir planlarının nasıl olması gerektiğinin yanında LNG ve Sıvılaştırılmış Petrol Gazı (LPG) taşıyan gemilere römorkör ve kılavuz kaptan almak zorunlu hale getirilmiș ve LNG gemilerinin geçiși için direkt olarak idareden izin alınmas1 zorunlu hale getirilmiştir (Küçükosman ve Bilgin, 2019). 2019 yılında İstanbul Boğazı'ndan 41 bin 112, Çanakkale Boğazı'ndan 43 bin 759 gemi geçtiği ve bu gemilerin 18,805'inin LNG, LPG, kimyasal ve ham petrol taşıyan tankerler olduğu bildirilmiştir (Ünal, 2020). İstanbul Boğazı'nda 2019 yılında toplam 15 gemi kazası yaşanırken, 141 gemi arızası meydana gelmiştir (Ünal, 2020). Denizcilik Federasyonu, İstanbul Boğazı'nın, dünyanın en riskli ve dar kanallarından bir tanesi olduğuna dikkat çekerek, LNG gemilerinin geçişlerine izin verilmemesini talep etmektedir (Yedi Deniz, 2015).

LNG çoğunlukla metandan oluşan kriyojenik bir sıvıdır. Buharlaştırıldığında, yanıcılık aralığı hacimce yaklaşık $\% 5$ ile \%15 arasındadır, yani bu konsantrasyon aralığında hava ile karışım yanıcıdır (Vanem, Antão, Østvik ve Comas, 2008). Bu nedenle, kriyojenik sıcaklıklarından kaynaklanan olası hasarlara ek olarak, LNG dökülmeleri havuz yangınları ve sürüklenen buhar bulutlarının tutuşması gibi tehlikelerle ilişkilendirilir. Sıvı haldeyken, LNG patlayıcı değildir ve LNG buharı, yalnızca yanıcılık aralığında ve kapalı veya yarı kapalı bir alanda hava ile karışım halinde tutuşturulduğunda patlayacaktır. Doğal gaz da boğulma tehlikesi de olușturabilir. LNG toksik değildir ve deniz ortamına dökülürse kalıcı olmayacaktır. LNG sudan daha hafiftir, bu nedenle suya dökülen LNG yüzer. LNG kalıcı veya toksik olmadığ için bir LNG sızıntısı deniz suyu kalitesini etkilemez. Kaynama ve kriyojenik etkiler fiziksel etkilerdir ve kısa sürelidir. Deniz ortamına bir LNG salınımı, insanlar üzerinde doğrudan etkilere neden olma potansiyeline sahiptir. LNG, $-161^{\circ} \mathrm{C}^{\prime} \mathrm{de}$ kriyojenik bir sıvı olduğundan, aşırı düşük sıcaklık, bir kişi etkilenen bölge içinde suda kalırsa, temas halinde ciddi donmaya neden olabilir. Bu etki, LNG buharlaşana kadar, genellikle 10 dakikadan az sürecektir. LNG su ile temas ettiğinde suyun donması olası değildir. Aksine, LNG su yüzeyinde yüzerken, su LNG'yi isıtarak buharlaşmasına ve yayılan bir bulut oluşturmasına neden olur. Kriyojenik etkiler, soğuk LNG buharılyla değil, LNG ile doğrudan temasla sınırlıdır. Bu, havuzlanmış LNG'nin hemen yakınında bulunan kişilerin boğulmasına yol açabilecek hava/su arayüzünde yüksek metan seviyeleri yaratacaktır. Bir tutuşturma kaynağı mevcutsa ve LNG buhar1 yanarsa, termal radyasyon ölümle sonuçlanacaktır. Kapalı alanlardaki LNG salınımları, oksijen eksikliği olan veya patlayıcı ortamlar oluşturarak çalışanlar için güvenlik riski oluşturabilir. LNG endüstrisinin güvenlik kayd,, insan sağllğ 1 ve güvenliği üzerindeki potansiyel etkiler göz önüne alındığında, önemli boyutta bir LNG salınımı olasılığ1 son derece düşük olsa da LNG'nin katastrofik bir sizintısından kaynaklanan, meydana gelmesi muhtemel olmasa da önemli olarak kabul edilir. Sıvılaştırılmış formda, LNG'nin hacmi oda sıcaklığında aynı miktardaki doğalgaza göre 600 kat daha azdır. Bu nedenle LNG nakliyesi, büyük miktarlarda doğal gazın uzun mesafelerde taşınmasının ekonomik bir yoludur. LNG, normal atmosfer basıncında taşınır ve depolanır ve LNG taşıyıcıları, LNG'yi denizde taşımak için amaca yönelik olarak inşa edilmiş tank gemileridir (Vanem ve ark., 2008). ABD Federal Yönetmeliklerinden 33 CFR 165.1709'da (2020) sıvı doğal gaz tankerlerinin transit seyirleri ve operasyonları sırasında çevresinde oluşturulan, güvenlik alanları ve uyulması gereken kurallar detayları açıkça verilmiştir. Amerika Ulusal Yangından Korunma Kurumunun NFPA 59A (2019) standardında, sıvılaştırılmış doğal gaz tesislerinin yeri, tasarımı, yapımı, güvenliği, işletimi ve bakımı için minimum yangından korunma, güvenlik ve ilgili gereksinimleri belirlenmiştir. NFPA 59A standardı LNG üreten, depolayan ve işleyen tesislerin yerleşimi, tasarımı, inşaatı, bakımı ve işletilmesi ve LNG ile ilgili personelin eğitimi için geçerliyken LNG araçlarının yakıt ikmali dâhil tüm LNG araç uygulamaları için geçerli değildir.

LNG dağılım modelleri, yoğun gaz bulutunun dağılımına odaklanır. Genel olarak, yoğun gaz dağılım modelleri, korelasyonlar, integral modeller, sığ katman modelleri ve hesaplamalı akışkanlar dinamiği (CFD) modelleri şeklinde kategorilere ayrilabilir (Wang, Liu, Qian ve Huang, 2017). Korelasyon dağılım modelleri deneysel modellerdir ve BrittereMcQuaid modeli, Gaussian modeli ve momentum ile enerjinin korunumuna dayanan 
modifiye edilmiş Gauss dağılım modelinin çeşitli formları korelasyon modellerine örnek verilebilir. $\mathrm{Bu}$ modellemeler, engellerin etrafındaki veya karmaşık arazi üzerindeki akışı modelleyemez (Siuta, Markowski ve Mannan, 2013). Öte yandan, PHAST (Süreç, Tehlike, Analiz, Yazılım Arac1 - Process, Hazard, Analysis, Software Tool), ALOHA (Tehlikeli Atmosferlerin Alansal Konumları - Areal Locations of Hazardous Atmospheres) ve FLACS (Alev Hizlandirma Yazılımı - Flame Acceleration Software) gibi integral modeller, korelasyon modellerinden çok daha karmaşıktır. Temel diferansiyel denklemlerin çözümlerini içerirler fakat karmaşı geometrinin etkilerini tahmin edemezler. LNG dağılım modelleri arasında Navier-Stokes akıșkanlar denklemlerini kullanarak LNG'nin dağılımını tanımlayan CFX, FLACS, FLOW-3d gibi CFD modelleri mevcuttur.

PHAST, ALOHA ve FLACS gibi yazilım programları kullanılarak yangın, patlama ve toksik dağılımın sonuçlarını modelleyen çeşitli çalışmalar bulunmaktadır. (Dadashzadeh, Khan, Hawboldt ve Amyotte, 2013; Hasani ve Nader, 2016; Inanlooi ve Tansel, 2015; Zareei, Nikou ve Shariati, 2016; Dasgotra, Varun Teja, Sharma ve Mishra, 2018; Özay, Keskin ve Uçan, 2020). Özay ve arkadaşları (2021) çalışmalarında endüstriyel tipte biogas tesisinde olabilecek metan patlamasını PHAST ve ALOHA programlarını karşılaştırmışlardır. Tseng ve arkadaşları (2012), Tayvan'daki üç farklı üretim tesisinde toksik kimyasal (klor, epiklorohidrin ve fosgen) salınım etkisinin ölçeklerini gösteren tehdit bölgelerini ALOHA yazılımı ile belirlemişlerdir. Başka bir araştırmada Çetinyokuş (2017), yanıcı madde (metan), zehirli siv1 (etilen diamin) ve zehirli gaz (metil klorür) olarak üç tehlikeli kimyasalın sonuç analizini ALOHA yazılımı ile incelemiş ve farklı atmosferik şartlarda, özellikle rüzgâr hızı, kararlılık sınıfi, seçilen üç tehlikeli kimyasal için tehdit bölgeleri içindeki etki mesafelerini bulmuştur. Ayrıca, Trávnícek ve araştırma arkadaşları (2018), tarımsal biyogaz tesislerindeki alev yı ğınlarını ALOHA yazılımı ile incelemiş ve metan gazının zemin seviyesinden daha yüksek seviyelerde daha hızlı seyreltileceğini bildirmişlerdir.

BLEVE (Kaynayan Sıvı Genişleyen Buhar Patlaması) en yıkıcı büyük tehlikelerden biri olarak kabul edilir ve özellikle LPG için kapsamlı bir şekilde çalışılmıştır. BLEVE tehlikesi geçmişte LNG depolaması için güvenilir bir olay olarak görülmemiştir. Bunun başlıca nedeni, LNG'nin genellikle atmosferik basınçta veya yakınında kriyojenik sıcaklıklarda depolanmasıdır (Pitblado, 2007). Son y1llarda kamyonlar ve feribotlar gibi ticari araçlar için LNG gibi daha temiz ve daha verimli yakıtların kullanılması yönünde bir eğilim olmuştur. Ticari kullanımda olan veya tasarım aşamasında olan bu sistemlerin çoğu, doğal kaynamayı azaltmak ve bazı işlemlerde LNG ürününün pompalanmasına yardımcı olmak için basınç altındadır.

LNG tanklarında BLEVE patlama potansiyelinin, özellikle vakum yalıtımlı çift cidarlı basınçlı bir kabın patlamasının inandırıcı bir senaryo olup olmadığı birçok tartışmanın konusu olmuştur (Betteridge ve Phillips, 2015). Şimdiye kadar endüstri, bu gemilerin mekanik darbe veya alev çarpması yoluyla muhafazasının kaybının inandırıcı olmadığını kanıtlamayı zor bulmuştur (Muhammed 2014). Ayr1 ayr1, tek cidarlı LNG tanker kamyonlarının dâhil olduğu iki BLEVE olayı İspanya'da rapor edilmiştir (Planas-Cuchi, Gasull, Ventosa ve Casal, 2004; Martinez, Perez ve Ayala 2011). Çift cidarlı LNG gemilerinin arızasının inandırıcılığı tartışılsa da, potansiyel bir LNG BLEVE tehlikeleri tahmin edebilmek için bir gereklilik vardır. Güvenli çalışmayı sürdürmek için tehlikeli senaryoları belirlemek önemlidir. $\mathrm{Bu}$ nedenle, çalıșmanın amacı, son derece kritik bir öneme sahip olan İstanbul Boğazı'ndan geçen LNG taşıyan tankerlerde olası bir tank patlaması ve BLEVE senaryosu durumunda kazanın etki alanlarını ALOHA yazılım programı kullanarak incelemektir.

\section{MATERYAL VE METOT ALOHA yazılımı}

$\mathrm{Bu}$ makale çalışmasında İstanbul Boğazında olası bir LNG tankı taşıyan tanker kazası sonucu, oluşabilecek patlamanın etkilerini modellemek için ALOHA yazılımı kullanılmış ve patlama senaryosu oluşturulmuştur. ALOHA, tehlikeli kimyasal gazların hareketini ve dağılımını tahmin etmek, gazların tanklardan veya gaz borularından sızan ve buharlaşan kimyasal salınımlarını ve tehlikeli gaz bulutu dağılımından atmosfere yayılma oranlarını ve etki alanlarını modellemek için kullanılan bir bilgisayar programıdır (EPA, 2017). ALOHA ayrıca, tehlikeli bir gaz bulutunun dağılımını tahmin etmek için salınan kimyasalın fiziksel özelliklerini ve salım senaryosunun gerçek zamanlı koşullarını kullanarak yanıcı bir gazın patlayabileceği alanı tahmin etmek 
için de kullanılabilir. ALOHA yazılımında, meteorolojik koșullar, kırsal ve kentsel alanlar gibi parametreler seçilerek kimyasal maddenin patlama ve atmosferik salınım sonuçları değerlendirilebilir. ALOHA'da hesaplanan grafik çıtılar ile MARPLOT yazılımı beraber kullanılarak haritalar üzerinde tesisin gerçek konumu ve etki alanları belirlenebilir (EPA, 2017). MARPLOT programı kimyasal acil durumları planlamak ve bunlara müdahale etmek için kullanılan coğrafi bilgi sistemleri arayüzlü bir haritalama programidır.
ALOHA direkt, sıvı birikintisi, tank veya boru gibi kaynak seçenekleri sunar. Sıv1 birikintisi seçeneği, sabit yarıçaplı bir sıvı birikintisi olduğunda seçilebilir. Sıvı, normal buharlaşan bir sıvı veya kaynayan bir sıvı olabilir. Tank seçeneği, kaynak yatay veya dikey bir silindir veya zemin seviyesinde tek delikli küresel bir tank olarak seçilebilir. Tank başlangıçta bir gaz, bir sıvı veya sıvılaştırılmış bir gaz içerebilir. İçerik, sıcaklık ve / veya basınç değişikliklerinin bir sonucu olarak faz değiştirebilir. Kaynak, zemin seviyesinde tek delikli basınçlı gaz içeren bir boru olduğunda boru seçeneği seçilebilir.

Tablo 1. ALOHA Programının Verileri

\begin{tabular}{ll}
\hline Parametreler & ALOHA Verileri \\
\hline Yerel Bilgiler & Türkiye, İstanbul \\
Kimyasal madde & Metan \\
CAS Numarası & $74-82-8$ \\
PAC değerleri & PAC-1: $65,000 \mathrm{ppm}$ \\
& PAC-2: $230,000 \mathrm{ppm}$ \\
& PAC-3: $400,000 \mathrm{ppm}$ \\
Alt patlama sınırı & LEL: $50,000 \mathrm{ppm}$ \\
Üst patlama sınırı & UEL: $150,000 \mathrm{ppm}$ \\
Tank tipi & Küresel \\
Tank çapı & $26.7 \mathrm{~m}$ \\
Tank Hacmi & $10000 \mathrm{~m}^{3}$ (100\% full) \\
Zemin Pürüzlülüğü & Açı su \\
Ölçüm yüksekliği & $3 \mathrm{~m}$ \\
Ortam sıcaklığ & $25^{\circ} \mathrm{C}$ \\
& $39.6^{\circ} \mathrm{C}$ (En Yüksek)* \\
Nem & $-5.1^{\circ} \mathrm{C}$ (En Düşük)* \\
Tank içindeki sıcaklık & $\% 50$ \\
\hline bul Yıllık Hava Sicaklığ 1 Ölçüm Periyodu & -1629 \\
\hline
\end{tabular}

Kaynak doğrudan bir nokta salımı ve sürekli bir hız emisyonu veya toplam kütlenin anlık salınımı olarak seçilebilir. Anlık veya sürekli olarak doğrudan salım tipi için, toplam kütle, kütle akıș hızı ve kaynak yüksekliği veri olarak sağlanmalıdır (Bhattacharya ve Kumar, 2015).

Ancak, yazılımın bazı sinırlamaları vardır. Sınırlamalardan biri; program kimyasal bileşiğin hızlı bir işlem olarak hava ile karıştırıldığını varsayar. Diğer sınırlama; nihai ürünleri, yani duman, partikül madde ve radyoaktif partikülleri tespit etme kabiliyeti yoktur. Bir başka sınırlama ise simülasyon çalışması sırasında rüzgar hızının ve rüzgar yönünün sabit olduğunun varsayılmasıdır (Yadav, Chaudhary ve Yadav, 2020).

\section{Senaryolar}

$\mathrm{Bu}$ çalışmanın senaryosu İstanbul Boğazında Boğaz köprüsünün altından geçen bir LNG gemisinde LNG tankında BLEVE patlaması olasıdır. Beaufort (Bofor) rüzgâr skalasına göre hafif rüzgârın en üst sınırı olan 10 knots rüzgâr hızı olarak seçilmiştir. Rüzgâr yönü seçiminde İstanbul Boğazı'nda en sık görülen yön (İnan, 1994) olan kuzeydoğu (NE) yönü seçilmiştir. Meteoroloji Genel Müdürlüğünün (2021) İstanbul ilinde yıllık hava sıcaklığı verilerine göre en yüksek ve en düşük sıcaklıklar alınarak meteorolojik şartlara göre 3 farklı senaryo oluşturulmuştur. Senaryo 1 'de $\mathrm{T}=25^{\circ} \mathrm{C}$, orta bulutlu ve nem $=\% 50$; Senaryo 2'de $\mathrm{T}=39.6^{\circ} \mathrm{C}$, bulutsuz ve nem $=\% 5$; Senaryo 3 'de $\mathrm{T}=-5.1 \mathrm{oC}$, tamamen bulutlu ve 
nem=\%99 seçilmiştir. Tablo 1'de ALOHA programına girilen veriler verilmiştir.

\section{TARTIŞMA VE SONUÇ}

ALOHA programı kullanılarak LNG taşıyan küresel tankta bir BLEVE patlaması sonucu oluşacak alev topunun 938 metre çapında ateş topu oluşacağını ve 41 saniye süre (Tablo 2) ile yanacağını hesaplanmıştır.

Tablo 3'de 10,000 $\mathrm{m}^{3}$ 'lük bir LNG tankında oluşan BLEVE patlamsının oluşturacağı meteorolojik şartları farklı 3 ayrı senaryo için termal radyasyon miktarlarına göre etki alanları ve etki alanı verilmiştir. Şekil 1'de MARLOT versiyon 5.1.1 bilgisayar programı ile ölçeklendirilerek küçültülmüş İstanbul haritası üzerinde Senaryo 1'in etki alanları gösterilmiştir. Kırmızı ile gösterilen 2.0 kilometrelik bölgede $10.0 \mathrm{~kW} / \mathrm{m}^{2}$ lik termal radyasyon oluşacağ 1 ve bu bölgenin 60 saniye içinde potansiyel olarak ölümcül olacağı hesaplanmıştır. Turuncu ile gösterilen 2.8 kilometrelik bölgede $5.0 \mathrm{~kW} / \mathrm{m}^{2}{ }^{\prime} l i k$ termal radyasyon oluşacağ 1 ve bu bölgede bulunanlarda 2. derece yanıklar oluşacağı öngörülmektedir. Sarı ile gösterilen 4.4 kilometrelik bölgede $2.0 \mathrm{~kW} / \mathrm{m}^{2}$ lik termal radyasyon oluşacağ 1 ve bu bölgede bulunan insanların ağrı duyacakları ve binaların camlarının kırılması beklenmektedir.

Senaryo 1, senaryo 2 ve senaryo 3 karşılaştırıldığında en yüksek etki alanının yaz aylarında yüksek sıcaklık $39.6^{\circ} \mathrm{C}$, bulutsuz ve nemsiz meteorolojik şartlarda olduğu görülmektedir. En düşük etki alanının ise senaryo $1^{\prime}$ de $25^{\circ} \mathrm{C}$ 'de, orta bulutlu ve orta nem seviyesinde olduğu belirlenmiştir. Değişik rüzgâr yön ve hızlarında da farklı senaryolar denenmiş ama sonuçlarda değişiklik görülmediği için ayrı senaryo oluşturulmamıştır ama oluşturması beklenmektedir. Patlama alanını daha detaylı modelleyen alternatif programlarda rüzgâr hızının da sonuçlarda farklılık yaratacağ düşünülmektedir.

Tüm LNG taşıyıcı türleri çift cidarlı gemilerdir, ancak bağımsız veya entegre kargo tanklarından oluşan farklı kargo muhafaza sistemleri mevcuttur. Mevcut LNG filolarında membranlı tank tasarımları ve küresel tank tasarımları olmak üzere iki ana tip gemi tasarımı (Şekil 2) hâkimdir (Vanem ve ark., 2008). Membranlı tank tasarımlarında, kargo muhafaza sistemi, gemi gövdesi tarafından yapısal olarak desteklenen çok ince bir invar veya paslanmaz çelik çift cidarlı, yalıtımlı kargo zarfından oluşur. Moss tankerleri olarak da adlandırılan küresel tank taşıyıcıları, geminin gövdesi içinde kendi kendini taşıyan küresel alüminyum tanklara veya prizmatik şekilli paslanmaz çelik tanklara sahiptir. Bu tanklar dışarıdan izole edilmiştir. Her iki tanker alternatifi de LNG'yi uzun mesafelerde taşımak için $-162{ }^{\circ} \mathrm{C}$ civarındaki sicakliklarda depolanan sofistike sistemlerle tasarlanmış, inşa edilmiş ve donatılmıştır.

Tablo 2. Küresel tankta yanıcı sivı, BLEVE patlaması

\begin{tabular}{ll}
\hline Parametreler & Veriler \\
Rüzgâr hızı, yönü & 10 knots, NE (Kuzeydoğu) \\
Kararlılık Sınıfı & E \\
Ateş Topundaki Tank Kütlesi Yüzdesi & $\% 100$ \\
Ateş Topu Çapı & 938 metre \\
Yanma Süresi & 41 saniye \\
\hline
\end{tabular}

Tablo 3. Tehdit Modellemesi: Ateş topundan gelen termal radyasyon

\begin{tabular}{lrrrrr}
\hline $\begin{array}{l}\text { Tehlike Bölgesi } \\
\text { Renk kodu }\end{array}$ & $\begin{array}{l}\text { Etki alanı } \\
\text { (Senaryo 1) }\end{array}$ & $\begin{array}{l}\text { Etki alanı } \\
\text { (Senaryo 2) }\end{array}$ & $\begin{array}{l}\text { Etki alanı } \\
\text { (Senaryo 3) }\end{array}$ & $\begin{array}{l}\text { Termal } \\
\text { Radyasyon } \\
\text { miktarı }\end{array}$ & Potansiyel Etki \\
\hline Kırmızı & $2.0 \mathrm{~km}$ & $2.2 \mathrm{~km}$ & $2.2 \mathrm{~km}$ & $10.0 \mathrm{~kW} / \mathrm{m}^{2}$ & $\begin{array}{l}60 \text { saniye içinde } \\
\text { potansiyel olarak } \\
\text { ölümcül } \\
\text { Turuncu }\end{array}$ \\
Sarı & $2.8 \mathrm{~km}$ & $3.2 \mathrm{~km}$ & $3.0 \mathrm{~km}$ & $5.0 \mathrm{~kW} / \mathrm{m}^{2}$ & $\begin{array}{l}60 \text { saniye içinde } 2 . \\
\text { derece yanıklar }\end{array}$ \\
& $4.4 \mathrm{~km}$ & $4.8 \mathrm{~km}$ & $4.7 \mathrm{~km}$ & $2.0 \mathrm{~kW} / \mathrm{m}^{2}$ & 60 saniye içinde ağr1 \\
\hline
\end{tabular}




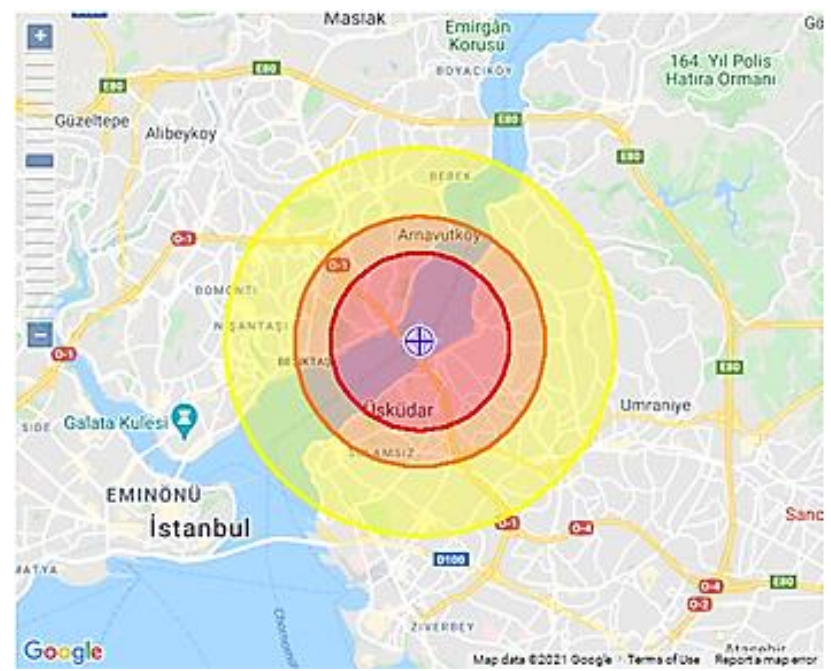

Şekil 1. Tehdit Modellemesi: Ateş topundan oluşan termal radyasyon (Senaryo 1)

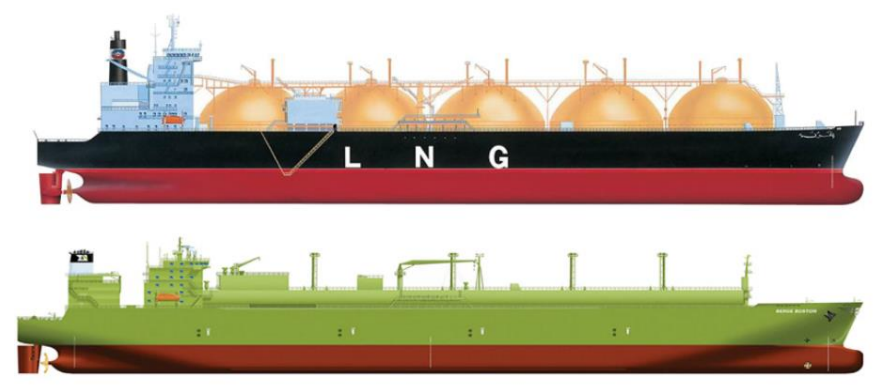

Şekil 2. Ana LNG taşıyıcı türleri: küresel yosun tankerleri (üstte) ve membran tankerleri (altta) (Vanem ve ark., 2008).

İlk LNG kargosunun 1959 yılında bir LNG tankeri ile taşınmasından bu yana LNG'nin deniz taşımacılığ 1 kademeli olarak artmıştır. LNG taşımacıllğının tarihçesi üzerine bir literatür araştırması, 6000 GRT'den büyük LNG taşıyıcılarının dahil olduğu 158 bilinen ilgili kazayı bildirmiş̦tir (Østvik, Vanem ve Castello, 2005). Bu kazalara göre LNG nakliye tarihi boyunca küresel tip LNG gemilerinde kazaların daha sik meydana geldiğini, ancak son 20 yılda membranlı gemilerde kazaların daha sık olduğunu göstermektedir. Tüm LNG taşıyıcı türleri için kazaların meydana geldiği belirtilmektedir (Vanem ve ark., 2008). Çoğunlukla LNG endüstrisinde mevcut olan bir sorun, kara veya açık deniz tesislerinde yeniden gazlaştırma ünitesindeki kritik depolama tankı bileşenidir(Mulyana, Muhammad, Saad, Mariah ve Riveli, 2017). Çoğunlukla aşırı basınç, korozyona bağlı arıza, malzeme bozulması, metal yüzeydeki gerilim, destek cihazındaki arıza, yani kontrol vanası, basınç emniyet valfi, pompa ve kompresördeki arıza ve diğer arızaların bir veya kombinasyonundan kaynaklanan arızalar kazaya neden olmaktadır (Mulyana ve ark., 2017). Bu arızalar, depolama tankında BLEVE ve yangina neden olabilmektedir. LNG depolama tankında meydana gelebilecek BLEVE ve yangınlar, aksam ve ekipman sisteminin emniyet güvenilirliğinin yanı sıra sabotaj veya başka sebeplerden kaynaklanan bir gemi kazası nedeni ile olabilir.

Hightower ve arkadaşları (2004) çalışmalarında su üzerine bir LNG sızıntısı nedeniyle kamu güvenliğine ve mülküne yönelik tehditleri, tehlikeleri, sonuçlanı ve riskleri analiz ederek, dört LNG sızıntı çalışmasını modelleyerek incelemişlerdir. Sonuçlar varsayımlardaki farklılıklar nedeniyle geniş bir sonuç yelpazesi göstermiştir. Çalışmada çarpışmalar ve karaya oturma gibi kazara LNG sızıntılarından kaynaklanan risklerin mevcut güvenlik politikaları ve kapsamlı, risk temelli 
yönetim ve planlama uygulamalarıyla yönetilebilir sonucuna varılmıștır. Bunun yanısıra, yangınlardan kaynaklanan termal tehlikeler nedeniyle, yaklaş1k 1600 m'den yakın mesafelerde halk sağlığı ve güvenliği etkileri olabileceğini belirtmişlerdir (Hightower ve ark., 2004). Büyük, tutuşmamış LNG buharı salınımı olası olmasada, buhar bulutları bir sızıntıdan 2500 m'ye kadar uzayabileceğini bildirmişlerdir (Hightower ve ark., 2004). Gerçek tehlike mesafeleri, ihlal ve dökülme boyutuna, sahaya özgü koşullara ve çevresel koşullara bağlı olacaktır.

Çalışmanın verileri incelendiğinde, İstanbul Boğazı gibi stratejik önem taşıyan bir bölgede böyle bir tanker kazasını hem insan sağlığı, hem çevre kirliliği hem de ulusal güvenlik açısından çok ciddi sonuçları olacağı aşikardır.

\section{SONUÇLAR}

Sonuç olarak LNG gemileri ve tankları patlama ve yangın risklerine karşı oldukça emniyetli üretilselerde, olası bir patlamanın İstanbul Boğazında çok büyük bir yıkıma yol açacağı görülmektedir. $\mathrm{Bu}$ çalışmada $10,000 \mathrm{~m}^{3}$ 'lük bir LNG tankında BLEVE patlaması modellenmiştir ki şu an aktif olarak yük taşıyan LNG gemileri birden fazla tank içermektedir. $\mathrm{Bu}$ sonuç patlamanın etkilerinin ve etki alanının çok daha olacağını göstermektedir. Mevcut LNG filonun ortalama boyutu yaklaşı $120,000 \mathrm{~m}^{3}$ iken, yakın gelecekte 200,000-250,000 $\mathrm{m}^{3}$ kapasiteli LNG süpertankerinin kullanılacağı öngörülmektedir. Mevcut durumda İstanbul Boğazından geçen tankerlerin taşıdığı tehlikeli madde yüzünden patlama riski, İstanbul Boğazında çok büyük bir felakete yol açabilir. Bu durumda gemi geçişlerinin kontrollü yapılması, kılavuzsuz hiçbir geminin geçmemesi, gemilerde risk değerlendirmelerinin siklıkla kontrol edilmesi ve riskli görülen durumlar için önceden önlem alınması önerilmektedir.

ALOHA programı gerçeğe yakın patlama modellemesi yapmakla beraber, programın pek çok kısıtlaması vardır. $\mathrm{Bu}$ çalışma bir ön çalışma niteliğinde olup daha sonraki aşamada daha gerçekçi sonuçlar vermesi için reel verilerle farklı modelleme yöntemi kullanılması tavsiye edilmektedir. Gelecekteki çalışmalarda PHAST programı kullanılarak, birden çok tankın domino etkisi ile patlama analizinin yapılması tavsiye edilir. Domino etkisi ile yapılacak modelleminin etki alanının çok daha fazla olacağı ve çok daha büyük bir yıkıma ve çevre felaketine yol açacağı tahmin edilebilir. Teknik olarak makina öğrenmesi ve yapay zeka uygulamaları kullanılarak tehlike durumlarını önceden haber veren bir sistemin kurulmas1 olas1 patlama olasıliklarının belirlenmesinde ve İstanbul Boğazı geçişi güvenlik açığının önlenmesinde faydalı olacaktır. Çalışmanın deniz emniyeti, deniz kazaları konusunda çalışan araştırmacılar, denizcilik sektörü, deniz taşımacılık ve sigorta şirketleri için faydalı olmasını ve patlama modellemesi olarak literatüre katkı sağlayamasını temenni ederiz.

\section{ÇIKAR ÇATIŞMASI BEYANI}

Yazar/ Yazarlar bu makale ile ilgili herhangi bir çıkar çatışması bildirmemektedir.

\section{ARAŞTIRMA VE YAYIN ETÍĞİ BEYANI}

Yazar/Yazarlar bu çalışmanın araştırma ve yayın etiğine uygun olduğunu beyan eder.

\section{KAYNAKLAR}

33 CFR 165.1709, (2020). Security Zones: Liquefied Natural Gas Tanker Transits and Operations at Phillips Petroleum LNG Pier, Cook Inlet, AK. https://www.law.cornell.edu/cfr/text/33/165.1709

Betteridge, S. ve Phillips, L. (2015). Large scale pressurised LNG BLEVE experiments. Symposium Series No 160.

Bhattacharya, R. ve Kumar, G.V. (2015). Consequence analysis for simulation of hazardous chemicals release using ALOHA software. International Journal of ChemTech Research, 8(4), 2038-2046.

Martinez, B.J.M., Perez, B.J. ve Ayala, M.J.A. (2011). Analysis of the explosion of a liquefied-natural-gas road-tanker. Seguridad y Medio Ambiente, 32, N127.

Çetinyokuş, S. (2017). Sonuç analizi ile belirlenen etki mesafeleri üzerine atmosferik seçimlerin etkisi (ALOHA yazılımı). Afyon Kocatepe Üniversitesi Fen ve Mühendislik Bilimleri Dergisi, 17 (1), 209217. DOI: https://doi.org/10.5578/fmbd.52776

Dadashzadeh, M., Khan, F., Hawboldt, K. ve Amyotte, P. (2013). An integrated approach for fire and explosion consequence modelling. Fire Safety Journal, 61, 324337. https://doi.org/10.1016/j.firesaf.2013.09.015

DOI:

Dasgotra, A., Varun Teja, G.V.V., Sharma, A. ve Mishra, K.B. (2018). CFD modelling of large-scale flammable cloud dispersion using FLACS. Journal of Loss Prevention in the Process Industries, 56, 531536. DOI: https://doi.org/10.1016/j.jlp.2018.01.001

EPA. (2017). ALOHA Software. Erişim adresi: https://www.epa.gov/cameo/aloha-software

Hasani F. ve Nader N. (2016). Consequence modelling and analysis of gas export compression unit using PHAST software. International Journal of Advanced Biotechnology and Research, 7 (5), 1344-1349. 
Hightower, M., Gritzo, L., Luketa-hanlin, A., Covan, J., Tieszen, S., Irwin, M., Kaneshige, M., Melof, B., Morrow, C., \& Ragland, D. (2004). Guidance on Risk Analysis and Safety Implications of a Large Liquefied Natural Gas (LNG) Spill Over Water. Sandia Report, SAND2004-6258, 167. https://doi.org/10.2172/882343

Inanloo, B. ve Tansel, B. (2015). Explosion impacts during transport of hazardous cargo: GIS-based characterization of overpressure impacts and delineation of flammable zones for ammonia. Journal of Environmental Management, 156, 1-9. DOI: https://doi.org/10.1016/j.jenvman.2015.02.044

İnan, M. (1994). İstanbul Boğazı Kuzeyinin Hakim Rüzgar Yönleri Ve Dalga Yüksekliklerinin Etüdü. Yüksek Lisans tezi, İstanbul Üniversitesi, Deniz Bilimleri ve İşletmeciliği Enstitüsü, Klimatoloji ve Meteoroloji Ana Bilim Dalı, İstanbul.

Küçükosman, B. ve Bilgin, G. (2019). Türk Boğazları ve Dünya Ham Petrol Ticareti: 2015-2018 Yılları Arasında Türkiye'den Geçen Ham Petrol Miktarı Analizi ve Petrol Piyasası Üzerine Olası Etkileri. Bilkent Enerji Notları, BEN 8. Erişim adresi: https://www.bilkenteprc.com/bilkentenergynotes

Meteoroloji Genel Müdürlüğü, (2021). https://www.mgm.gov.tr/veridegerlendirme/il-veilceler-istatistik.aspx?m=ISTANBUL

Montreaux Sözleşmesi, (1936). https://www.kiyiemniyeti.gov.tr/userfiles/file/mevzu at/Montreux\%20Bo\%C4\%9Fazlar\%20S\%C3\%B6zl e\%C5\%9Fmesi.pdf

Mulyana, C., Muhammad, F., Saad, A. H., Mariah ve Riveli, N. (2017). Failure analysis of storage tank component in LNG regasification unit using fault tree analysis method (FTA). AIP Conference Proceedings, 1827. Erişim adresi: https://doi.org/10.1063/1.4979430

NFPA 59A, (2019). Standard for the Production, Storage, and Handling of Liquefied Natural Gas (LNG). https://www.nfpa.org/codes-and-standards/all-codesand-standards/list-of-codes-andstandards/detail? code $=59 \mathrm{~A}$

Østvik, I., Vanem, E. ve Castello, F. (2005). HAZID for LNG tankers. SAFEDOR report D.4.3.1.

Özay M.E., Güzel P. ve Can E. (2021). Consequence Modelling and Analysis of Methane Explosions: A preliminary Study on Biogas Stations. Journal of Advanced Research in Natural and Applied Sciences, 6(1), 132-144. doi.org/10.28979/jarnas.890649

Özay M.E., Keskin U. ve Uçan R. (2020). Doğalgaz Kazannda Metan Gazı Patlaması İçin Katastrofik Yırtılma ve Sızıntı Senaryolarının Phast Modelleme Programı ile Değerlendirilmesi. 1. Uluslararsı Hazar Bilimsel Araştırmalar Kongresi, 230-243.
Pitblado, R.M. (2007). Potential for BLEVE associated with marine LNG vessel fires. Journal of Hazardous Matterials, 140, 527-534.

Planas-Cuchi, E., Gasull, N., Ventosa, A. ve Casal, J. (2004). Explosion of a road tanker containing liquefied natural gas. Journal of Loss Prevention in Process Industries, 17, 315-321.

Siuta, D. Markowski, A.S. ve Mannan, M.S. (2013). Uncertainty Techniques in Liquefied Natural Gas (LNG) Dispersion Calculations. Journal of Loss Prevention in the Process Industries, 26(3), 418-426. https://doi.org/10.1016/j.jlp.2012.07.020

Trávnícek, P., Kotek, L., Nejtek V., Koutný T., Junga P. ve Vítěz T. (2018). Quantitative analyses of biogas plant accidents in Europe. Renewable Energy, 122, 89-97. DOI: https://doi.org/10.1016/j.renene.2018.01.077

Tseng, J.M., Su, T.S. ve Kuo, C.Y. (2012). Consequence evaluation of toxic chemical releases by ALOHA. Procedia Engineering, 45, 384-389. DOI: https://doi.org/10.1016/j.proeng.2012.08.175

Türk Boğazları Deniz Trafik Düzeni Yönetmeliği, (2019). https://www.mevzuat.gov.tr/MevzuatMetin/21.5.142 6.pdf

Ünal, A.Y. (2020). Boğazları kullanan gemi sayısı 85 bine yaklaştı. Anadolu Ajansı, Erişim adresi: https://www.aa.com.tr/tr/turkiye/bogazlari-kullanangemi-sayisi-85-bine-yaklasti/1700127

Vanem, E., Antão, P., Østvik, I. ve Comas, F.D.C. (2008). Analysing the risk of LNG carrier operations. Reliability Engineering and System Safety, 93(9), 1328-1344. https://doi.org/10.1016/j.ress.2007.07.007

Wang, K., Liu, Z., Qian, X. ve Huang, P. (2017). Longterm consequence and vulnerability assessment of thermal radiation hazard from $L N G$ explosive fireball in open space based on full-scale experiment and PHAST. Journal of Loss Prevention in The Process Industries, 46, 13-22. https://doi.org/10.1016/j.jlp.2017.01.001

Yadav, R., Chaudhary, S., Yadav, B.P., Varadharajan, S. ve Tauseef, S.M. (2020). Assessment of Accidental Release of Ethanol and Its Dangerous Consequences Using ALOHA. Advances in Industrial Safety, Springer Singapore.

Yedi Deniz. (2015). LNG gemileri 55 atom bombas1 gücünde. Erişim adresi: https://www.7deniz.net/mhaber-16220.html

Zareei, H., Nikou M.K. ve Shariati A. (2016). A consequence analysis of the explosion of spherical tanks containing liquefied petroleum gas (LPG). Iranian Journal of Oil \& Gas Science and Technology, 5 (3), 32-44. 